\title{
Comparison of exogenous surfactant therapy, mechanical ventilation with high end-expiratory pressure and partial liquid ventilation in a model of acute lung injury $\dagger$
}

\author{
A. Hartog1, G. F. Vazquez de Anda ${ }^{1}$, D. Gommers' ${ }^{1}$, U. Kaisers ${ }^{2}$, S. J. C. Verbrugge ${ }^{1}$, \\ R. Schnabel ${ }^{3}$ and B. Lachmann ${ }^{1 *}$ \\ ${ }^{1}$ Department of Anaesthesiology (Room Ee 2393), Erasmus University Rotterdam, PO Box 1738, 3000 DR \\ Rotterdam, The Netherlands. ${ }^{2}$ Department of Anaesthesiology and Intensive Care Medicine, Virchow Clinics, \\ Humboldt University, Augustenburger Platz 1, 13353 Berlin, Germany. ${ }^{3}$ Department of Pathology, \\ Ruhr University Bochum, Universitätsstrasse 150, D-44780 Bochum, Germany \\ *To whom correspondence should be addressed \\ $\dagger$ Presented in part at the 5th European Society of Anaesthesiologists Annual Meeting, May 3-6, 1997, Lausanne, \\ Switzerland
}

\begin{abstract}
We have compared three treatment strategies, that aim to prevent repetitive alveolar collapse, for their effect on gas exchange, lung mechanics, lung injury, protein transfer into the alveoli and surfactant system, in a model of acute lung injury. In adult rats, the lungs were ventilated mechanically with $100 \%$ oxygen and a PEEP of $6 \mathrm{~cm} \mathrm{H}_{2} \mathrm{O}$, and acute lung injury was induced by repeated lung lavage to obtain a $\mathrm{Pa}_{2}$ value $<13 \mathrm{kPa}$. Animals were then allocated randomly $(n=12$ in each group) to receive exogenous surfactant therapy, ventilation with high PEEP ( $18 \mathrm{~cm} \mathrm{H} \mathrm{H}_{2} \mathrm{O}$ ), partial liquid ventilation or ventilation with low PEEP $\left(8 \mathrm{~cm} \mathrm{H}_{2} \mathrm{O}\right)$ (ventilated controls). Blood-gas values were measured hourly. At the end of the 4-h study, in six animals per group, pressure-volume curves were constructed and bronchoalveolar lavage (BAL) was performed, whereas in the remaining animals lung injury was assessed. In the ventilated control group, arterial oxygenation did not improve and protein concentration of BAL and conversion of active to non-active surfactant components increased significantly. In the three treatment groups, $\mathrm{Pa}_{\mathrm{O}_{2}}$ increased rapidly to $>50 \mathrm{kPa}$ and remained stable over the next $4 \mathrm{~h}$. The protein concentration of BAL fluid increased significantly only in the partial liquid ventilation group. Conversion of active to non-active surfactant components increased significantly in the partial liquid ventilation group and in the group ventilated with high PEEP. In the surfactant group and partial liquid ventilation groups, less lung injury was found compared with the ventilated control group and the group ventilated with high PEEP. We conclude that although all three strategies improved $\mathrm{Pa}_{\mathrm{O}_{2}}$ to $>50 \mathrm{kPa}$, the impact on protein transfer into the alveoli, surfactant system and lung injury differed markedly.
\end{abstract}

$\mathrm{BrJ}$ Anaesth 1999; 82: 81-6

Keywords: model, respiratory distress; ventilation, mechanical; ventilation, positive endexpiratory pressure; lung, injury; lung, lavage; lung, surfactant; fluorocarbons

Accepted for publication: August 17, 1998

Acute lung injury (ALI) is a condition of acute respiratory failure in which lack of active surfactant leads to alveolar collapse, resulting in severe hypoxia. ${ }^{1}$ Available treatments include mechanical ventilation with high inspiratory oxygen concentrations and high peak alveolar pressures with large distending tidal volumes, but these are known to induce lung damage. ${ }^{2}$ Ventilation strategies that prevent repeated alveolar collapse are thought to prevent further progression of lung damage. ${ }^{3}$ Therefore, new treatment strategies that aim to prevent repetitive alveolar collapse during ALI are under investigation.
These new strategies include: (1) pressure-controlled ventilation that recruits collapsed lung areas by applying an inspiratory pressure that overcomes the opening pressure of collapsed but recruitable lung units. After recruitment, ventilation pressures are reduced and PEEP is set just above the critical closing pressure of these lung units to prevent end-expiratory collapse. ${ }^{4}$ (2) Partial liquid ventilation, in which ventilation is superimposed on lungs that are filled with perfluorocarbons thus preventing expiratory collapse. ${ }^{67}$ (3) Exogenous surfactant therapy, in which the lost active surfactant is replaced. ${ }^{89}$ 
Studies have shown that these strategies improve oxygenation while diminishing the effects on lung injury in animal models of ALI. ${ }^{4} 10$ All three strategies are currently under investigation for clinical use, and although results are promising, they have not been compared directly. ${ }^{11-15}$ In this study, we have compared these three techniques for their efficacy in improving arterial oxygenation and lung mechanics in rats who underwent bronchoalveolar lavage, and assessed their impact on transfer of protein into the alveoli, the surfactant system and on lung injury.

\section{Materials and methods}

The study was approved by the University's Animal Experimental Committee, and the care and handling of the animals conformed with European Community guidelines (86/609/EC). The study was performed in 60 adult male Sprague-Dawley rats (body weight 270-330 g). After induction of anaesthesia with $2 \%$ enflurane and $65 \%$ nitrous oxide in oxygen, a polyethylene catheter was inserted into a carotid artery for obtaining arterial blood samples. Before tracheostomy, the animals received pentobarbital (pentobarbitone) $60 \mathrm{mg} \mathrm{kg}-1$ i.p. (Nembutal, Algin BV, Maassluis, the Netherlands). After tracheostomy, neuromuscular block was produced with pancuronium $1 \mathrm{mg} \mathrm{kg}^{-1}$ i.m. (Pavulon, Organon Teknika, Boxtel, the Netherlands) followed immediately by connection to a ventilator. The animals underwent mechanical ventilation with a Servo Ventilator 300 (Siemens-Elema, Solna, Sweden) in a pressure constant time-cycled mode, at an inspired oxygen concentration $\left(F_{\mathrm{I}_{\mathrm{O}_{2}}}\right)$ of 1.0 , frequency $30 \mathrm{bpm}$, peak inspiratory pressure (PIP) $12 \mathrm{~cm} \mathrm{H}_{2} \mathrm{O}$, positive end-expiratory pressure (PEEP) $2 \mathrm{~cm} \mathrm{H}_{2} \mathrm{O}$ and inspiratory/expiratory (I/E) ratio 1:2. Anaesthesia was maintained with pentobarbital $40 \mathrm{mg} \mathrm{kg}^{-1} \mathrm{~h}^{-1}$ i.p. and neuromuscular block was maintained with pancuronium $1 \mathrm{mg} \mathrm{kg}^{-1} \mathrm{~h}^{-1}$ i.m. Body temperature was maintained within the normal range using a heating pad. Immediately after induction of anaesthesia 12 animals were killed and served as healthy controls.

Acute lung injury was induced by repeated bronchoalveolar lavage (BAL) $\left(32 \mathrm{ml} \mathrm{kg}^{-1}\right)$ with warm saline $\left(37^{\circ} \mathrm{C}\right)$, according to Lachmann and colleagues. ${ }^{16} \mathrm{BAL}$ was repeated as often as necessary to produce a $\mathrm{Pa}_{\mathrm{O}_{2}}<13 \mathrm{kPa}$ at a PIP and PEEP of 26 and $6 \mathrm{~cm} \mathrm{H}_{2} \mathrm{O}$, respectively. Within 10 min of the last lavage, the animals were allocated randomly to one of the following groups ( $n=12$ each). In the first group, the lungs were opened by increasing PIP to $40 \mathrm{~cm} \mathrm{H}_{2} \mathrm{O}$ and PEEP to $20 \mathrm{~cm} \mathrm{H}_{2} \mathrm{O}$, and the I/E ratio was set at 1:1. After 2-3 min, PIP was decreased to $35 \mathrm{~cm} \mathrm{H}_{2} \mathrm{O}$ and PEEP to $18 \mathrm{~cm} \mathrm{H}_{2} \mathrm{O}$, and arterial blood-gas values were obtained. Ventilator settings remained unchanged for the rest of the study. The second group received an intratracheal bolus dose of perfluorocarbon $15 \mathrm{ml} \mathrm{kg}$ (APF175A; Perfluoro-dimethyldecalin, Fluoro-Seal Inc, Round Rock, USA) after disconnection from the ventilator. APF-
$175 \mathrm{~A}$ is a perfluorocarbon with a density of $1.98 \mathrm{~g} \mathrm{ml}^{-1}$, vapour pressure $0.09 \mathrm{kPa}$, surface tension $20.5 \mathrm{dyn} \mathrm{cm}^{-1}$ and oxygen solubility $35 \mathrm{ml} \mathrm{O}_{2}$ per $100 \mathrm{ml}$ perfluorocarbon per atmosphere of oxygen pressure (all values at $25^{\circ} \mathrm{C}$ ). During the study, evaporation losses of perfluorocarbon were compensated for by administering substitution doses. The substitution doses were based on our previous experience with this model, and aimed at maintaining $\mathrm{Pa}_{\mathrm{O}_{2}}$ constant during the rest of the study. The third group received exogenous surfactant at a dose of $120 \mathrm{mg} \mathrm{kg}^{-1}$. The surfactant used was isolated from minced pig lungs, prepared as described previously. ${ }^{17}$ The freeze-dried material was suspended in warm saline to a concentration of $40 \mathrm{mg} \mathrm{ml}^{-1}$ and administered intra-tracheally, after disconnection from the ventilator. The surfactant suspension was administered as a bolus followed by a bolus of air (12 $\mathrm{ml} \mathrm{kg}^{-1}$ ), directly into the tracheal tube via a syringe, and was followed immediately by re-connection to the ventilator. In the fourth group, ventilator pressures were increased by $2 \mathrm{~cm} \mathrm{H}_{2} \mathrm{O}$ (PIP/PEEP of $28 / 8 \mathrm{~cm} \mathrm{H}_{2} \mathrm{O}$ ) to prevent critical hypoxia and remained unchanged throughout the study. This group served as ventilated controls.

Arterial blood-gas samples were obtained before lavage, after lavage and hourly for $4 \mathrm{~h}$. Samples were analysed for arterial oxygen tension $\left(\mathrm{Pa}_{\mathrm{O}_{2}}\right)$ and arterial carbon dioxide tension $\left(\mathrm{Pa}_{\mathrm{CO}_{2}}\right)$ using an electrochemical blood-gas analyser (ABL 505, Radiometer, Copenhagen, Denmark).

At the end of the experiment, the animals were killed by an overdose of pentobarbital. Six animals from each group were selected randomly for histopathological examination. The lungs of these animals were fixed, sectioned and stained as described previously. ${ }^{18} \mathrm{~A}$ semi-quantitative morphometric analysis of lung injury was performed under blinded conditions by a pathologist (R. S.) who scored atelectasis, oedema, vascular wall thickening and leucocyte infiltration as none, light, moderate or severe (score $0,1,2$ or 3 , respectively). Lung injury score was defined as the average of all variables for each group.

The remaining animals from each group were used to assess lung mechanics. Static pressure-volume curves were recorded using conventional techniques. ${ }^{16}$ Total lung capacity $\left(\mathrm{TLC}_{35}\right)$ was defined as lung volume at inflation with a distending pressure of $35 \mathrm{~cm} \mathrm{H}_{2} \mathrm{O}$. After pressure-volume recordings, BAL was performed five times with saline$\mathrm{CaCl}_{2} 1.5 \mathrm{mmol}$ litre ${ }^{-1}$. The active surfactant component in BAL fluid was separated from the non-active component by differential centrifugation followed by subsequent phosphorus analysis, and the ratio between non-active and active components (small aggregate to large aggregate (SA/LA) ratio) was calculated, as described previously. ${ }^{19}$ Protein concentration of BAL fluid was determined using the Bradford method (Bio-Rad protein-assay, Munich, Germany). ${ }^{20}$

Statistical analysis was performed using the Instat statistical package. Inter-group comparisons were analysed using ANOVA and intra-group comparisons by repeated measures 
ANOVA. If ANOVA resulted in $P<0.05$, a Tukey-Kramer post-test was performed. All data are reported as mean (SD) and $P<0.05$ was considered statistically significant.

\section{Results}

Blood-gas values before and immediately after lavage were comparable in all groups (Fig. 1, Table 1). None of the animals died during the 4-h observation period. In the ventilated control group, $\mathrm{Pa}_{\mathrm{O}_{2}}$ did not improve, whereas it increased to pre-lavage values and remained stable during the 4-h study in the surfactant-treated group and the group ventilated with high PEEP (Fig. 1). In the partial liquid ventilation group, administration of a bolus dose of perfluorocarbon $15 \mathrm{ml} \mathrm{kg}^{-1}$ resulted in significant improvement in $\mathrm{Pa}_{2}$ but pre-lavage values were not reached (Fig. 1). Perfluorocarbon was substituted periodically to compensate for evaporation loss and the substitution dose of perfluorocarbon was $1.1(0.4) \mathrm{ml} \mathrm{kg}^{-1} \mathrm{~h}^{-1}$.

$\mathrm{Pa}_{\mathrm{CO}_{2}}$ data are give in Table $1 . \mathrm{Pa}_{\mathrm{CO}_{2}}$ decreased significantly in both the surfactant-treated group and the partial liquid ventilation group, and was significantly lower in the surfactant-treated group compared with the other groups (Table 1).

Figure 2 shows the deflation limbs of the pressurevolume curves. At deflation less than $15 \mathrm{~cm} \mathrm{H}_{2} \mathrm{O}$, lung

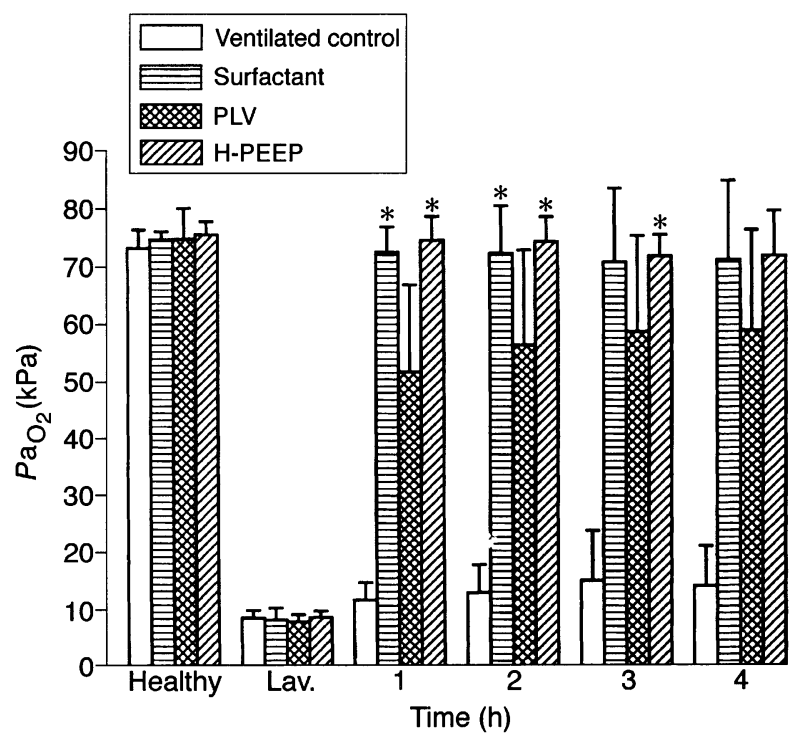

Fig 1 Mean (SD) $\mathrm{Pa}_{\mathrm{O}_{2}}$ values in the ventilated control, surfactant-treated, partial liquid ventilation (PLV) and high (H) PEEP groups. $* P<0.05$ vs PLV group. volume in the healthy controls exceeded lung volume in all other groups, other than the group treated with surfactant. $\mathrm{TLC}_{35}$ was significantly decreased in the ventilated control group, but not in the three treatment groups, compared with healthy controls.

Protein concentration of BAL fluid was significantly increased in both the partial liquid ventilated group and the ventilated control group compared with healthy control animals (Fig. 3). SA/LA ratio, the ratio between non-

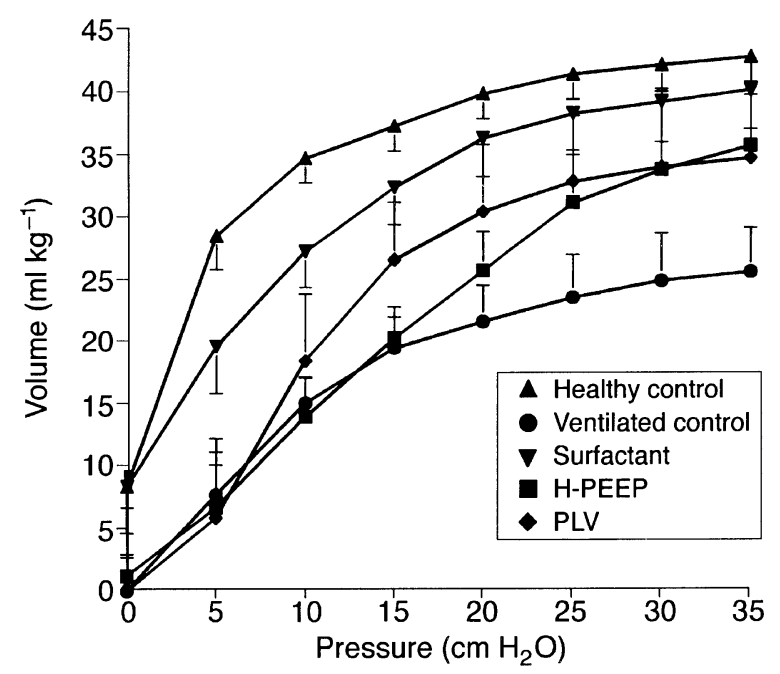

Fig 2 Deflation limbs from the pressure-volume curves (mean (SD)) in the healthy control, ventilated control, surfactant-treated, partial liquid ventilation (PLV) and high (H) PEEP groups. Volume is lung volume above FRC. At deflations less than $15 \mathrm{~cm} \mathrm{H}_{2} \mathrm{O}$, lung volume in the healthy controls exceeded lung volume in all other groups, except the surfactanttreated group. $\mathrm{TLC}_{35}$ was decreased only in the ventilated control group compared with the healthy control group.

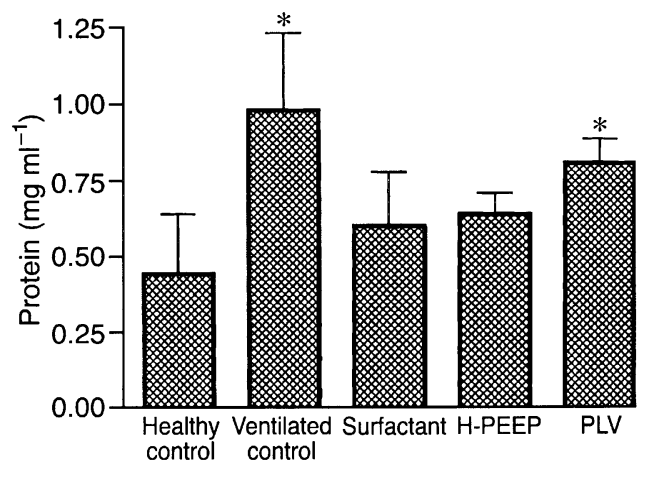

Fig 3 Mean (SD) protein concentration of BAL fluid in the healthy control, ventilated control, surfactant-treated, partial liquid ventilation (PLV) and high $(\mathrm{H})$ PEEP groups. ${ }^{*} P<0.05$ vs healthy control group.

Table $1 \mathrm{~Pa}_{\mathrm{CO}_{2}}$ (mean (SD)); values (kPa) in the four treatment groups, before lavage (Healthy), immediately after lavage (Lav.) and 1, 2, 3 and $4 \mathrm{~h}$ after lavage. $* P<0.05$ compared with surfactant group; $\uparrow P<0.05$ vs control group; $\ddagger P<0.05$ vs Lav. Control=ventilated controls with low PEEP; H-PEEP $=$ high PEEP; PLV $=$ partial liquid ventilation; $S U R F=$ exogenous surfactant therapy

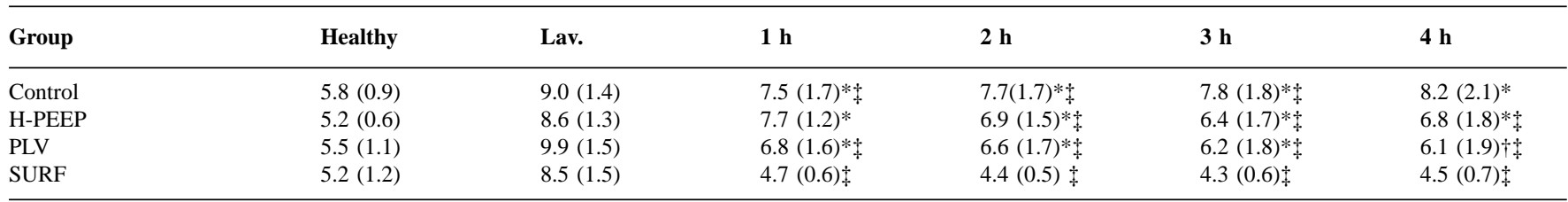




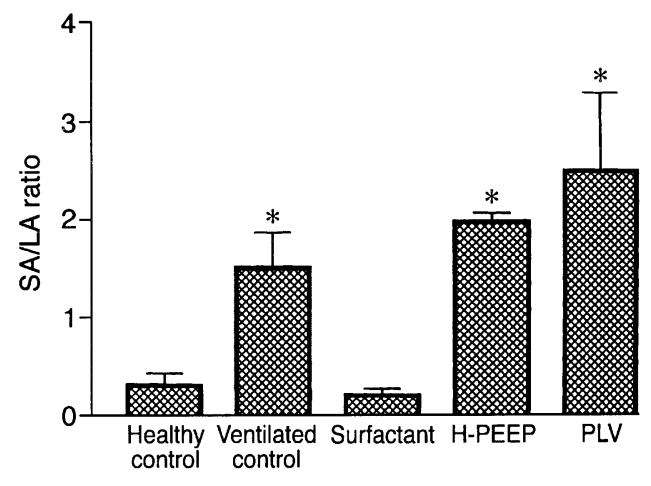

Fig 4 Ratio between non-active and active surfactant components (mean (SD)) in the healthy control, ventilated control, surfactant-treated, partial liquid ventilation $(\mathrm{PLV})$ and high $(\mathrm{H})$ PEEP groups $(\mathrm{SA} / \mathrm{LA}=$ small to large aggregates). ${ }^{*} P<0.05$ vs healthy control group.

Table 2 Total phosphorus recovered from bronchoalveolar lavage fluid (mean (SD)) (h). $* P<0.05$ vs healthy controls (Healthy); $\dagger P<0.05$ vs all other groups. Control=ventilated controls with low PEEP; H-PEEP=high PEEP; PLV= partial liquid ventilation; surfactant $=$ exogenous surfactant therapy

\begin{tabular}{|c|c|}
\hline & Total phosphorus $\left(\mu \mathrm{mol} \mathrm{ml} \mathbf{l}^{-1}\right)$ \\
\hline Healthy & $0.14(0.06)$ \\
\hline Control & $0.05(0.01)^{*}$ \\
\hline H-PEEP & $0.05(0.01)^{*}$ \\
\hline PLV & $0.05(0.01)^{*}$ \\
\hline Surfactant & $0.45(0.05) \dagger$ \\
\hline
\end{tabular}

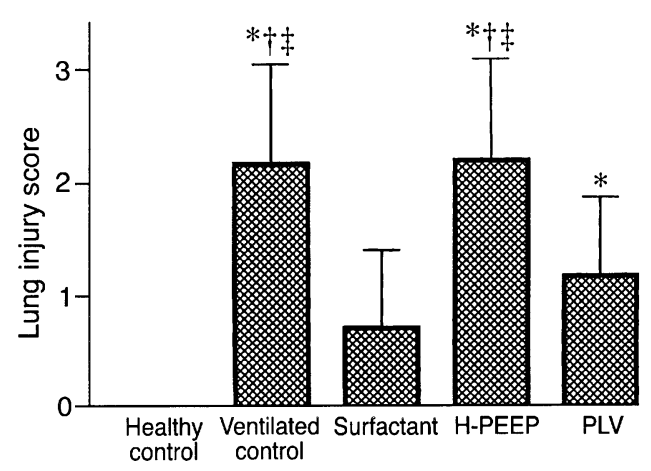

Fig 5 Lung injury score (mean (SD)) in the healthy control, ventilated control, surfactant-treated, partial liquid ventilation (PLV) and high (H) PEEP groups. $* P<0.05$ vs healthy control group; $\uparrow P<0.05$ vs surfactant group; $\ddagger P<0.05$ vs PLV group.

active and active surfactant components, was significantly increased in the ventilated control group, the group ventilated with high PEEP and the partial liquid ventilation group, but not in the surfactant-treated group (Fig. 4). Compared with healthy control animals, the total amount of phosphorus in BAL fluid, measured to quantify the phospholipidcontaining surfactant system, was significantly lower in the ventilated control group, the group ventilated with high PEEP and the partial liquid ventilation group (Table 2).

Semi-quantitative lung injury analysis showed that in both the surfactant and partial liquid ventilation groups, lung injury was significantly lower than in the two groups that were ventilated only (high and low PEEP) (Fig. 5).
However, only in the surfactant group, lung injury was not significantly increased compared with healthy controls.

\section{Discussion}

We have shown that although exogenous surfactant therapy, ventilation with high PEEP and partial liquid ventilation increased $\mathrm{Pa}_{\mathrm{O}_{2}}$ to greater than $50 \mathrm{kPa}$, the impact on transfer of proteins into the alveoli, lung injury and on the surfactant system differed markedly. Ventilation with high PEEP and exogenous surfactant therapy prevented transfer of proteins into the alveoli, whereas partial liquid ventilation did not. Conversion of active to non-active surfactant aggregates was increased in both the partial liquid ventilation group and the group ventilated with high PEEP, but not in the surfactant-treated group. Lung injury score was reduced in both the partial liquid ventilation and surfactant groups compared with the groups that were ventilated only.

The sustained improvement in $\mathrm{Pa}_{\mathrm{O}_{2}}$ to pre-lavage values in the group ventilated with high PEEP indicates that applied PIP and PEEP were sufficient to open the lungs and keep them open (Fig. 1). That alveolar recruitment and stabilization in this group was a result of mechanically counterbalancing the increased retractive forces and not recovery of the endogenous surfactant system, was evident by the lack of improvement in surfactant variables of BAL fluid determined at the end of the study (Table 2). However, protein concentration of BAL fluid was not increased during the 4-h ventilation period with high PEEP. This is important as plasma proteins are known to inhibit surfactant function in a dose-dependent manner. ${ }^{21}$ Therefore, protein leakage may mediate the destructive chain of events that lead to further progression of lung injury. The clinical significance of these findings in this high PEEP group remains to be determined, but studies by Kesecioglu, Tibboel and Lachmann $^{11}$, and recently by Amato and colleagues ${ }^{12}$, have shown improvement in $\mathrm{Pa}_{\mathrm{O}_{2}}$ in patients when using an 'open lung' strategy, and provided the first results indicating that the technique is associated with a decrease in morbidity and mortality. ${ }^{22}$

In surfactant-deficient lungs, partial liquid ventilation with perfluorocarbons has been shown to provide adequate gas exchange, which was confirmed in our study (Fig. 1). ${ }^{1023}$ However, despite the high $\mathrm{Pa}_{\mathrm{O}_{2}}$ values which indicate that the lungs were kept open, we found that transfer of proteins into alveoli was increased after partial liquid ventilation for $4 \mathrm{~h}$ (Fig. 2). The mechanism responsible for this is not known. It is hypothesized that improvement in gas exchange with partial liquid ventilation results from filling the collapsed atelectatic alveoli in the dependent part of the lung with the non-compressible, high-density perfluorocarbons, thus preventing end-expiratory collapse. In the non-dependent part of the lung, a thin film of perfluorocarbons is formed at the air-liquid interface because of evaporation of perfluorocarbons from the lower lung regions. ${ }^{23}$ We speculate that as a result of the low 
constant surface tension of perfluorocarbons, the retractive forces in the non-dependent part of the lung are reduced, resulting in large volume changes at small increments in pressure, making the lungs prone to epithelial overstretching, which has been shown to damage the alveolar-capillary membrane leading to increased transfer of proteins into the alveoli ${ }^{24}$ (for review see Dreyfuss and Saumon ${ }^{25}$ ). This mechanism is supported by the study of Cox and colleagues ${ }^{26}$ who showed that during partial liquid ventilation, perfluorocarbon is distributed predominantly to the lower lung regions, whereas gas ventilation takes place in the upper lung regions. Furthermore, several pathology studies have demonstrated significant variance in lung injury between non-dependent and dependent lobes after partial liquid ventilation, with greater non-dependent lobe damage. ${ }^{27} 28$

In our study, the partial liquid ventilation and surfactant groups underwent ventilation with the same PIP and PEEP pressures, but protein concentration of BAL fluid from the surfactant group was not increased (Fig. 2). Pulmonary surfactant has the unique property of reducing surface tension in parallel with a decrease in alveolar radius, thus keeping the ratio of surface tension/radius of the alveolus constant and preventing epithelial overstretching. Furthermore, as seen in the surfactant-treated group, a lower lung injury score was found in the partial liquid ventilation group despite increased transfer of protein into the alveoli. This probably reflects a direct effect of perfluorocarbon on inflammation processes, as in vitro evidence suggests a decrease in alveolar macrophage and neutrophil adherence, chemotaxis, phagocytosis and superoxide release. ${ }^{29} 30$

Total lung capacity at a distending pressure of $35 \mathrm{~cm}$ $\mathrm{H}_{2} \mathrm{O}\left(\mathrm{TLC}_{35}\right)$ was decreased only in the ventilated control group (Fig. 3). As substances with surface tension lowering properties were administered into the lungs of the partial liquid ventilation group and the surfactant-treated group, it is not surprising that TLC $_{35}$ was preserved in these groups. However, preservation of $\mathrm{TLC}_{35}$ in the group ventilated with high PEEP, but decreased $\mathrm{TLC}_{35}$ in the ventilated control group is striking as there were no differences in recovery of pulmonary surfactant between these groups (Fig. 4, Table 2). We speculate that the difference in $\mathrm{TLC}_{35}$ is explained by the difference in transfer of protein into the alveoli between these two groups, because of inhibition of the already compromised surfactant function by plasma proteins, as mentioned above.

In our study, we used the lung lavage model which has been studied extensively and is considered a reliable model of acute lung injury. ${ }^{16}$ Repeated whole-lung lavage produced an acute quantitative surfactant deficiency and, together with conventional mechanical ventilation leading to severe lung injury with impaired gas exchange, decreased lung compliance and FRC, increased permeability changes of the alveolo-capillary membrane with oedema, and sustained pulmonary hypertension. ${ }^{16} 1731$ Despite the fact that lung injury in this study was not representative of the pathology in humans with ALI, this model is ideal for testing interventions which may prove therapeutic for acute lung injury. 4617

In summary, we have shown that although exogenous surfactant therapy, mechanical ventilation with high PEEP and partial liquid ventilation opened up the lungs and kept them open, as indicated by the high $\mathrm{Pa}_{\mathrm{O}_{2}}$ values, the impact on pulmonary function differed markedly. Only with exogenous surfactant therapy was there improvement in all variables. Some studies have reported physiological and pathological benefits of partial liquid ventilation or ventilation with high PEEP in combination with exogenous surfactant, but whether any of these hybrid techniques has advantages over the use of exogenous surfactant alone has yet to be confirmed.

\section{Acknowledgements}

This work was supported financially by the International Foundation for Clinically Oriented Research (IFCOR). Equipment and material were made available by Siemens Elema AB, Solna, Sweden, and by Fluoro-Seal Inc, Round Rock, USA. We thank Mr Edwin Hendrik for expert technical assistance, and the Department of Paediatrics at the Erasmus University Rotterdam for assisting with phosphorus measurements. We also thank Mrs Laraine Visser-Isles for English language editing.

\section{References}

I Lewis JF, Jobe AH. Surfactant and the adult respiratory distress syndrome. Am Rev Respir Dis 1993; 147: 218-33

2 Houmes RJM, Bos JAH, Lachmann B. Effect of different ventilator settings on lung mechanics: with special reference to the surfactant system. Appl Cardiopulm Pathophysiol 1994; 5: II7-27

3 Muscedere G, Mullen JBM, Gan K, Slutsky AS. Tidal ventilation at low airway pressures can augment lung injury. Am J Respir Crit Care Med 1994; 149: 1327-34

4 Lachmann B, Jonson B, Lindroth M, Robertson B. Modes of artificial ventilation in severe respiratory distress syndrome: Lung function and morphology in rabbits after wash-out of alveolar surfactant. Crit Care Med 1982; 10: 724-32

5 Lachmann B, Danzmann E, Haendly B, Jonson B. Ventilator settings and gas exchange in respiratory distress syndrome. In: Prakash $\mathrm{O}$, ed. Applied Physiology in Clinical Respiratory Care. The Hague: Nijhoff, 1982; 14I-76

6 Tütüncü AS, Faithfull NS, Lachmann B. Intratracheal perfluorocarbon administration combined with mechanical ventilation in experimental respiratory distress syndrome: Dosedependent improvement of gas exchange. Crit Care Med 1993; 2 I: 962-9

7 Tutuncu AS, Akpir K, Mulder P, Erdmann W, Lachmann B. Intratracheal perfluorocarbon administration as an aid in the ventilatory management of respiratory distress syndrome. Anesthesiology 1993; 79: 1083-93

8 Lachmann B, Fujiwara T, Chida S, et al. Surfactant replacement therapy in the experimental acute respiratory distress syndrome (ARDS). In: Cosmi EV, Scarpelli EM, eds. Pulmonary Surfactant System. Amsterdam: Elsevier, 1983; 231-5

9 Häfner D, Beume R, Kilian U, Kraznai G, Lachmann B. Doseresponse comparisons of five lung surfactant factor (LSF) preparations in an animal model of adult respiratory distress syndrome (ARDS). Br J Pharmacol 1995; I I 5: 45I-8

10 Hirschl RB, Tooley R, Parent A, Johnson K, Bartlett RH. Improvement of gas exchange, pulmonary function, and lung injury with partial liquid ventilation. Chest 1995; 108: 500-8 
I I Kesecioglu J, Tibboel D, Lachmann B. Advantages and rationale for pressure control ventilation. In: Vincent JL, ed. Yearbook of Intensive Care and Emergency Medicine. Berlin: Springer-Verlag, 1994; 524-33

12 Amato MBP, Barbas CSV, Medeiros DM, et al. Beneficial effects of the 'open lung approach' with low distending pressures in acute respiratory distress syndrome. Am J Respir Crit Care Med 1995; I 52: 1845-36

I3 Hirschl RB, Pranikoff T, Gauger P, et al. Liquid ventilation in adults, children, and full-term neonates. Lancet I995; 346: I20I-2

I 4 Gauger PG, Pranikoff T, Schreiner RJ, Moler FW, Hirschl RB. Initial experience with partial liquid ventilation in pediatric patients with acute respiratory distress syndrome. Crit Care Med 1996 24: $16-22$

I5 Gregory TJ, Steinberg KP, Spragg R, et al. Bovine surfactant therapy for patients with acute respiratory distress syndrome. Am J Respir Crit Care Med 1997; I55: I309-I5

16 Lachmann B, Robertson B, Vogel J. In vivo lung lavage as an experimental model of the respiratory distress syndrome. Acta Anaesthesiol Scand 1980; 24: 23I-6

I7 Gommers D, Vilstrup C, Bos JAH, et al. Exogenous surfactant therapy increases static lung compliance, and cannot be assessed by measurements of dynamic compliance alone. Crit Care Med 1993; 2 I: 567-74

I 8 Kaisers U, Max M, Schnabel R, et al. Partial liquid ventilation with FC 3280 in experimental lung injury: Dose-dependent improvement of gas exchange and lung mechanics. Appl Cardiopulm Pathophysiol 1996; 6: 163-70

19 Veldhuizen RAW, Inchley K, Hearn SA, Lewis JF, Possmayer F. Degradation of surfactant associated protein B (SP-B) during in vitro conversion of large into small surfactant aggregates. Biochem J 1993; 295: |41-7

20 Bradford MM. A rapid and sensitive method for the quantitation of microgram quantities of protein utilizing the principle of proteindye binding. Ann Biochem 1976; 72: 248-54
2 I Lachmann B, Eijking EP, So KL, Gommers D. In vivo evaluation of the inhibitory capacity of human plasma on exogenous surfactant function. Intensive Care Med 1994; 20: 6-II

22 Amato MBP, Barbas CSV, Medeiros DM, et al. Effect of a protective-ventilation strategy on mortality in the acute respiratory distress syndrome. N Engl J Med 1998; 338: 347-54

23 Tütüncü AS, Faithfull NS, Lachmann B. Comparison of ventilatory support with intratracheal perfluorocarbon administration and conventional mechanical ventilation in animals with acute respiratory failure. Am Rev Respir Dis 1993; I48: 785-92

24 Egan EA, Nelson RM, Olver RE. Lung overinflation and alveolar permeability to non-electrolytes in the adult sheep in vivo. J Physiol 1976; 260: 409-24

25 Dreyfuss D, Saumon G. Ventilator-induced lung injury: Lessons from experimental studies. Am J Respir Crit Care Med 1998; I57: 294-323

26 Cox PN, Morris K, Frndova H, Babyn P, Bryan AC. Relative distribution of gas and perfluorocarbon (PFC) during partial liquid ventilation (PLV). Pediatr Res 1996; 39: 45A

27 Mrozek JD, Smith KM, Bing DR, et al. Exogenous surfactant and partial liquid ventilation. Am J Respir Crit Care Med 1997; I56: 1058-65

28 Smith KM, Bing DR, Meyers PA, et al. Partial liquid ventilation: a comparisson using conventional and high frequency techniques in an animal model of acute respiratory failure. Crit Care Med 1997; 25: II 79-86

29 Smith TM, Steinhorn DM, Thusu K, Fuhrman BP, Dandona P. A liquid perfluorochemical decreases the in vitro production of reactive oxygen species by alveolar macrophages. Crit Care Med 1995; 23: 1533-9

30 Virmani R, Fink LM, Gunter K, English D. Effect of perfluorochemical blood substitutes on human neutrophil function. Transfusion 1984; 24: 343-7

3 I Burger R, Bryan AC. Pulmonary hypertension after postlavage lung injury in rabbits: possible role of polymorphonuclear leukocytes. J Appl Physiol 199I; 7I: 1990-5 